Check for updates

Cite this: RSC Adv., 2017, 7, 48166

Received 1st September 2017

Accepted 21st September 2017

DOI: $10.1039 / \mathrm{c} 7 \mathrm{ra0} 9747 f$

rsc.li/rsc-advances

\section{Synthesis of a hemoglobin-conjugated triblock copolymer for oxygen carrying and specific recognition of cancer cells $\uparrow$}

\begin{abstract}
Huixuan Bu, Xin Xu, Jiaming Chen, \$Y Yuecheng Cuił and Li-Qun Wang (D) *
Tumour hypoxia, which has a negative effect on most anti-cancer treatments, has caused extensive concern over recent years. Concerned with this issue, this paper reports a hemoglobin-based oxygen nanocarrier (HBOC) functionalized with oxygen carrying and cancer cell recognition ability. First, the triblock copolymer poly[2-(methacrylamido) glucopyranose]-b-poly(methacrylicacid)-bpoly(butylmethacrylate) (PMAG- $b$-PMAA- $b$-PBMA), in which the first block consists of glucose units, was synthesized and characterized. Following the self-assembly of the amphiphilic copolymer into micelles in phosphate buffer solution, hemoglobin was conjugated onto the micelles through a condensation reaction between the carboxyl groups on PMAA and the amino groups on $\mathrm{Hb}$. The HBOC, with a mean diameter of around $147 \mathrm{~nm}$, is stable and disperses homogeneously in phosphate buffer solution. In addition, an in vitro cytotoxicity study revealed that the $\mathrm{HBOC}$ is biocompatible. More importantly, this HBOC was demonstrated to hold excellent capacity for oxygen binding. Moreover, cellular uptake indicated that the HBOC was internalized more easily by cancer cells than normal cells, which means that the HBOC shows specific recognition of cancer cells. Therefore, the hemoglobin-conjugated polymer that we prepared could be a promising nanocarrier for tumour therapy.
\end{abstract}

\section{Introduction}

Since the ability to accurately measure oxygen concentration in human tumours became possible in the 1990s, it was found that hypoxia is a specific characteristic of human tumours. ${ }^{1}$ Previously, partial pressures of oxygen in different kinds of human tumour were integrated and analyzed by a literature method, and it was reported that the partial pressure of oxygen in human tumours is less than $5 \mathrm{mmHg}$, much lower than that in normal tissues. ${ }^{2}$ It has been documented that hypoxia has a negative impact on radiotherapy, ${ }^{3}$ chemotherapy, ${ }^{4}$ as well as photodynamic therapy ${ }^{5}$ due to its influences on tumour metastasis, ${ }^{6}$ angiogenesis ${ }^{7}$ and genes. ${ }^{8}$ In addition, hypoxia tends to increase mutation rate, ${ }^{9}$ which reduces the curability of cancer. Recently, nanocarriers that target tumour hypoxia have shown more and more advantages, and can be divided into the following kinds: (1) targeting hypoxia inducible factor $(\mathrm{HIF}-1 \alpha)$; $^{10}$ (2) hypoxiaresponsive nanocarriers; ${ }^{11}$ (3) anaerobe modified nanocarriers; ${ }^{12}$ (4) oxygen-loaded polymer bubbles; ${ }^{13}$ (5) oxygen generator-loaded nanocarriers; ${ }^{\mathbf{1 4}} \quad$ (6) artificial oxygen

The Department of Polymer Science and Engineering of Zhejiang University, No. 38, Zheda Road, Hangzhou, Zhejiang, 310027, China. E-mail: lqwang@zju.edu.cn; 21529012@zju.edu.cn

† Electronic supplementary information (ESI) available. See DOI: 10.1039/c7ra09747f

\$ These authors contributed equally to this work. nanocarriers. ${ }^{15}$ The first three kinds of nanocarrier utilize hypoxia to reinforce selective delivery of anti-cancer agents, whereas all of the last three kinds improve tumour oxygenation intrinsically to enhance the efficiency of cancer therapy. Compared with oxygen-loaded polymer bubbles and oxygen generator-loaded nanocarriers, hemoglobin-based oxygen nanocarriers are more controllable, stable, safe and biocompatible without inorganics, such as $\mathrm{MnO}_{2}$ and $\mathrm{H}_{2} \mathrm{O}_{2}$, and have been demonstrated as promising artificial oxygen nanocarriers in recent studies. ${ }^{16-18}$

Hemoglobin ( $\mathrm{Hb}$ ) has the capacity to reversibly bind to four oxygen molecules. Free $\mathrm{Hb}$ exhibits negative effects, such as low circulation time and low stability, and consequently is unfit to be an oxygen carrier directly. ${ }^{19} \mathrm{Hb}$ modified nanocarriers, including micelles and vesicles, could overcome these shortcomings, and exhibit better ability for binding oxygen. ${ }^{\mathbf{1 6}}$ Furthermore, the nanosize enables $\mathrm{Hb}$ to more easily permeate through tumour vasculature. ${ }^{18}$ Recently, it has been documented many times that $\mathrm{Hb}$ has been entrapped into micelles or vesicles. Lu et al. ${ }^{20}$ prepared Hb-loaded nanoparticles using the double emulsion (w/o/w) technique. In this work, PEG- $b$ PLGA was used as a biodegradable polymeric layer to protect $\mathrm{Hb}$ from the surrounding tissue. A controlled hemorrhage model was applied to test the in vivo oxygenation of the Hb-loaded nanoparticles. The nanoparticles were demonstrated to hold an effective oxygen supply capacity in vivo. Wang et al. ${ }^{21}$ fabricated poly(lactide-co-diazidomethyl trimethylene carbonate)- $g$ - 
poly(ethylene glycol) [P(LA-co-DAC)-g-PEG] as a protein carrier. $\mathrm{Hb}$ was successfully loaded into the polymers via a thin film rehydration method. The incorporation of $\mathrm{Hb}$ was confirmed by SDS-polyacrylamide gel electrophoresis (SDS-PAGE). They also recorded UV-vis spectra to test the capacity for reversible binding to oxygen. However, to achieve entrapment, polymers were dissolved in organic solvents to form a homogeneous solution, which was later mixed with an aqueous solution of proteins under vigorous stirring or ultrasonication. These operations can damage protein activity. ${ }^{22}$ In order to solve this problem, approaches by which $\mathrm{Hb}$ is conjugated onto micelles can be used. Click chemistry and condensation reactions are widely preferred for conjugation of $\mathrm{Hb}$. Li et al. ${ }^{23}$ synthesized Hb-conjugated micelles based on PEG-PMPC-PLA, where pendant propargyl groups were introduced, via a click reaction between the propargyl groups and azido groups of azidized $\mathrm{Hb}$. The $\mathrm{O}_{2}$-binding ability was characterized by UV-vis spectroscopy. Qi et al. ${ }^{24}$ synthesized Hb-conjugated micelles via a thiol Michael addition reaction. Firstly, mPEG- $b$-PMAC- $b$-PCL, in which the middle block contains double bonds, was synthesized by sequential addition methods. Then, thiolated Hb was conjugated to the triblock copolymer. Hb-conjugated micelles could also be obtained through a condensation reaction between the amino groups of $\mathrm{Hb}$ and the carboxyl groups on polymers such as PEG- $b$-PMCC- $b$-PLA. ${ }^{25}$ Comparing them, it is found that the condensation reaction is milder and controllable, since new functional groups are not acquired and some damage to the protein can be avoided.

To enhance the accumulation of nanocarriers in cancer cells and avoid the toxicity against normal cells, investigators modified the surface of nanocarriers with different kinds of targeting ligand, such as peptides, ${ }^{26}$ folate,${ }^{27}$ antibodies ${ }^{28}$ and GM-CSF. ${ }^{29}$ Recently, investigators found that some transporters, whose efficiency in the transportation of small molecules is higher than that in receptors, are overexpressed on the surface

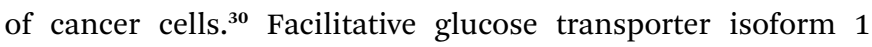
(GLUT1), which is responsible for transporting glucose to nourish cells, is included. This is due to the fact that cancer cells present an enormous consumption of glucose in a hypoxic environment. Furthermore, GLUT1 expressed on the surface of cancer cells shows a higher transportation rate than that for normal cells. ${ }^{31}$ Accordingly, a nanocarrier modified with glucose molecules can actively recognize cancer cells via GLUT1 and show an enhanced accumulation in cancer cells via a transporter-mediated pathway.

In this work, we designed a nanocarrier functionalized with oxygen carrying ability and specific recognition of cancer cells, as shown in Scheme 1. First, PMAG- $b$-PMAA- $b$-PBMA, in which the PMAG block is used for the specific recognition of cancer cells via GLUT1 and the PMAA block is used to conjugate with $\mathrm{Hb}$, was prepared as an amphiphilic triblock polymer via reversible addition-fragmentation chain transfer (RAFT) polymerization. Hb was conjugated on the micelles via a condensation reaction to form Hb-conjugated micelles (HCMs), which were confirmed to be non-toxic against cancer cells and normal cells. The conjugation of $\mathrm{Hb}$ was characterized by SDS-PAGE. Furthermore, the $\mathrm{Hb}$ conjugated onto the micelles still holds

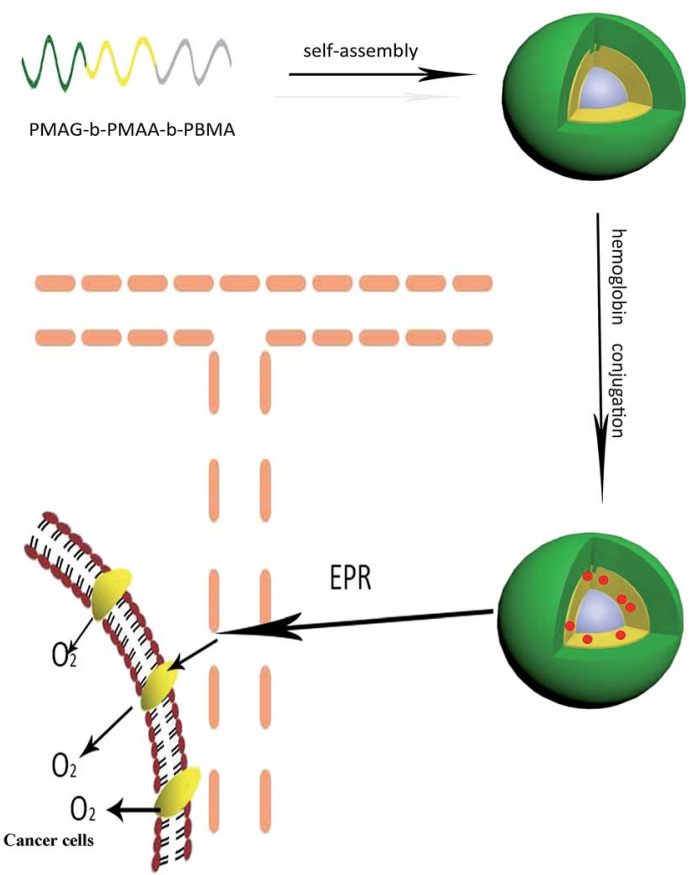

Scheme 1 Illustration of the stepwise formation and GLUT1-mediated accumulation in cancer cells of the hemoglobin-based nanocarrier.

excellent $\mathrm{O}_{2}$ binding ability. Moreover, in order to investigate cellular uptake of the HCMs by confocal laser scanning microscopy (CLSM) and flow cytometry, DOX was entrapped into the HCMs as a fluorescent molecule. In addition, the morphology, hydrodynamic diameter and stability of the PMAG$b$-PMAA- $b$-PBMA micelles and HCMs were also investigated.

\section{Experimental}

\subsection{Materials}

D-(+)-Glucosamine hydrochloride (98\%) and methacryloyl chloride (stabilized with MEHQ) were purchased from Tokyo Chemistry Industry and used as received. Doxorubicin (DOX, $>98 \%$ ) was purchased from Adamas Reagent Co. Ltd. 2Cyanoprop-2-yl-adithionaphthalate (CPDN) was synthesized in our group's previous work. 2,2'-Azobis (isobutyronitrile) (AIBN) (Aladdin, 98\%) was recrystallized three times from ethanol before use. Methacrylic acid (MAA) (TCI, 99\%) and butyl methacrylate (BMA) (TCI, 99\%) were passed through a column of activated neutral and basic alumina respectively before use. $N$-(3-(Dimethylamino)propyl)- $N^{\prime}$-ethylcarbodiimide hydrochloride (EDC, 98.5\%) and sodium hyposulfite were purchased from Aladdin Reagent Co. Ltd. and used without any further purification. Bovine hemoglobin ( $\mathrm{Hb}, \mathrm{Mr}=68000)$ was purchased from Shanghai Yuanju Biological Technology Co. Ltd. All other solvents and reagents were purchased from Sinopharm Chemical Reagent Co. Ltd. and preprocessed on the basis of standard methods. For the cell experiments, Hela cells and Hek 293 cells were purchased from the type culture collection of the Shanghai Institute for Biological Sciences, Chinese Academy of Sciences. Dulbecco's Modified Eagle's Medium (DMEM) and 1640 were 
obtained from GIBCO Invitrogen Corporation. Fetal bovine serum (FBS) was purchased from Hangzhou Sijiqing Bioengineering Material Co. Ltd. 4',6-Diamidino-2-phenylindole (DAPI), 3-(4,5 dimethylthiazol-2-yl)-2,5-diphenyl tetrazolium bromide (MTT) and dimethyl sulfoxide (DMSO) were used directly as received.

\subsection{Synthesis of 2-(methacrylamido)glucopyranose (MAG)}

MAG was synthesized as described previously. ${ }^{32}$ Glucosamine hydrochloride $\left(5.0 \mathrm{~g}, 2.32 \times 10^{-2} \mathrm{~mol}\right)$ and potassium carbonate $\left(3.2 \mathrm{~g}, 2.32 \times 10^{-2} \mathrm{~mol}\right)$ were added to a flask, then dissolved in $250 \mathrm{~mL}$ of methanol under stirring. Then the reaction mixture was cooled to $-10^{\circ} \mathrm{C}$ with a methanol/ice bath. Next, methacryloyl chloride $\left(2.25 \mathrm{~mL}, 2.32 \times 10^{-2} \mathrm{~mol}\right)$ was instilled dropwise into the reaction solution. After stirring at $-10{ }^{\circ} \mathrm{C}$ for $30 \mathrm{~min}$, the reaction was conducted at room temperature for $3 \mathrm{~h}$. The crude mixture was filtered using a sintered funnel to remove precipitated salts under vacuum. Then an off-white slurry was obtained after the filtrate was concentrated using reduced pressure. The slurry was purified through a chromatography column with dichloromethane/ methanol (ratio $4: 1$ ) as the eluent. A white solid was obtained as the final product with a yield of $50 \%$.

\subsection{Synthesis of the polymers}

The PMAG- $b$-PMAA- $b$-PBMA triblock polymer was synthesized via sequential RAFT polymerization according to Scheme 2.

Synthesis of PMAG. In brief, MAG $\left(0.5 \mathrm{~g}, 2.02 \times 10^{-3} \mathrm{~mol}\right)$ was dissolved in $4 \mathrm{~mL}$ of $\mathrm{N}, \mathrm{N}$-dimethylacetamide (DMF) held in a dry glass ampoule with a stirrer. Then, AIBN $(2.7 \mathrm{mg}, 1.65 \times$ $\left.10^{-5} \mathrm{~mol}\right)$ and CPDN $\left(22.6 \mathrm{mg}, 8.34 \times 10^{-5} \mathrm{~mol}\right)$ were simultaneously added. After bubbling with argon for $1 \mathrm{~h}$, the ampoule was sealed. The reaction was conducted under stirring at $70{ }^{\circ} \mathrm{C}$ for $24 \mathrm{~h}$ and then stopped by cooling with ice water. In order to remove impurities, the crude product was dialyzed against distilled water using a membrane (MWCO: 3500) for 2 days. The
PMAG homopolymer was obtained as a pink powder through lyophilisation with a yield of $90 \%$.

Synthesis of PMAG- $b$-PMAA. PMAG $\left(0.1 \mathrm{~g}, 1.67 \times 10^{-5} \mathrm{~mol}\right)$ was dissolved in $1 \mathrm{~mL}$ of DMF, and then added to a dry glass ampoule with a stirrer. After that, MAA $\left(0.169 \mathrm{~mL}, 1.99 \times 10^{-3}\right.$ $\mathrm{mol})$ and AIBN $\left(0.68 \mathrm{mg}, 4.17 \times 10^{-6} \mathrm{~mol}\right)$ were simultaneously added. After bubbling with argon for $1 \mathrm{~h}$, the ampoule was sealed. The reaction was conducted under stirring at $70{ }^{\circ} \mathrm{C}$ for $24 \mathrm{~h}$ and then stopped by cooling with ice water. Pure PMAG- $b$ PMAA was obtained by the same purification procedure as that of PMAG. The PMAG- $b$-PMAA block copolymer was obtained as a pink powder with a yield of $90 \%$.

Synthesis of PMAG- $b$-PMAA- $b$-PBMA. PMAG- $b$-PMAA (0.1 g, $6.127 \times 10^{-6} \mathrm{~mol}$ ) as a macro RAFT agent was dissolved in $1.4 \mathrm{~mL}$ of DMF, and added to a dry glass ampoule with a stirrer. BMA $\left(130.7 \mathrm{mg}, 9.19 \times 10^{-4} \mathrm{~mol}\right)$ and AIBN $(0.335 \mathrm{mg}, 2.04 \times$ $10^{-6} \mathrm{~mol}$ ) were simultaneously added. The following procedures were the same as those to synthesize PMAG and PMAG- $b$ PMAA. The crude product was washed and precipitated three times with a large excess of anhydrous ether, and then dried under vacuum for $24 \mathrm{~h}$. The final triblock copolymer was obtained as a white powder with a yield of $78 \%$.

\subsection{Preparation of the micelles}

PMAG- $b$-PMAA- $b$-PBMA (100 mg) was dissolved in DMF (20 mL). The solution was dialyzed against phosphate buffer solution ( $\mathrm{pH}$ 7.4) for 3 days using a membrane (MWCO: 3500). Then the PMAG- $b$-PMAA- $b$-PBMA micelles were collected and stored at $4{ }^{\circ} \mathrm{C}$ until use.

\subsection{Conjugation of $\mathrm{Hb}$ onto the PMAG- $b$-PMAA- $b$-PBMA micelles}

The carboxyl groups on the PMAG- $b$-PMAA- $b$-PBMA polymer were firstly activated with $\mathrm{EDC} \cdot \mathrm{HCl}$. The concrete procedure is that $\mathrm{EDC} \cdot \mathrm{HCl}(20 \mathrm{mg}, 0.104 \mathrm{mmol})$ was added to the prepared solution of the micelles ( $4 \mathrm{mg} \mathrm{mL} \mathrm{m}^{-1}, 5 \mathrm{~mL}$ ), whose $\mathrm{pH}$ had been adjusted to 7.0. After the mixture was stirred in an ice bath for
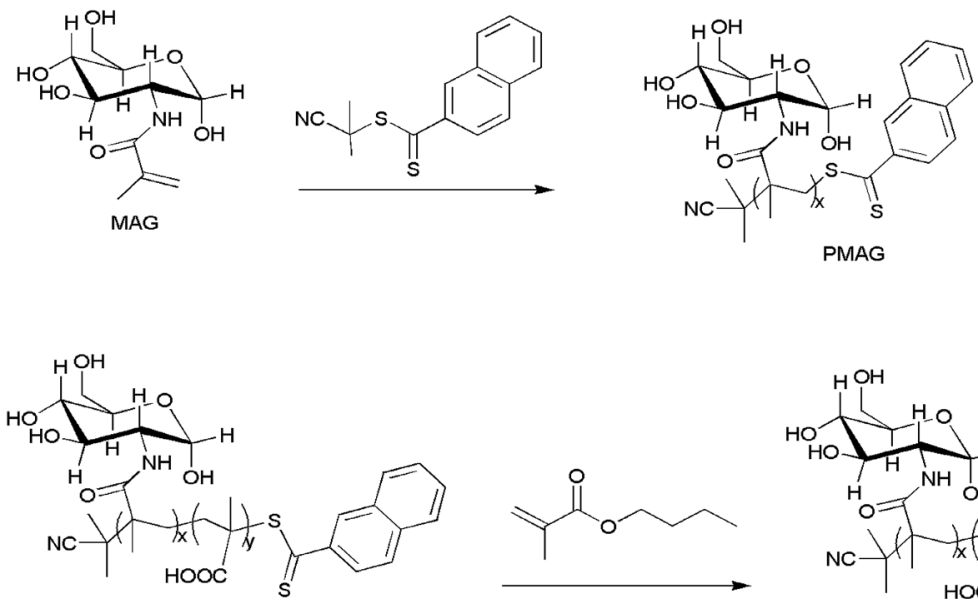

PMAG-b-PMAA

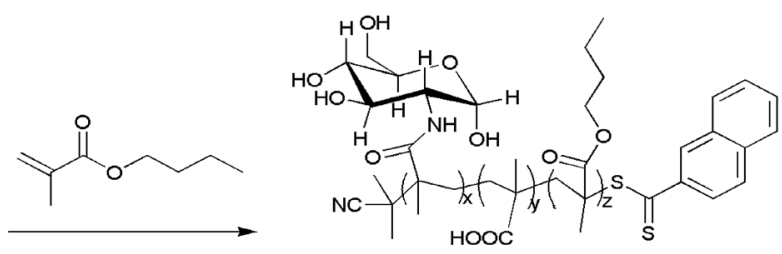

PMAG-b-PMAA-b-PBMA

Scheme 2 Synthesis of the triblock copolymer PMAG-b-PMAA- $b-P B M A$. 
$15 \mathrm{~min}, 567 \mu \mathrm{L}$ of $\mathrm{Hb}$ solution ( $0.073 \mathrm{mM}, \mathrm{pH} 7.4)$ was added dropwise, and then the mixture was stirred for $24 \mathrm{~h}$ at room temperature. Free $\mathrm{Hb}$ was removed by dialysis against phosphate buffer solution ( $\mathrm{pH}$ 7.4) for 2 days using a membrane (MWCO: 100 000) and the HCMs were obtained. The conjugation of $\mathrm{Hb}$ onto the micelles was assayed by SDS-PAGE, in which a $4 \%$ stacking gel and a $12 \%$ separating gel in a Mini-Protean II apparatus (Bio-Rad) were used, as presented in the literature. ${ }^{33}$ Samples, including free $\mathrm{Hb}, \mathrm{Hb}$ physically mixed with the polymer and the HCMs, were prepared at $0.5 \mathrm{mg} \mathrm{mL}^{-1}$ in Tris buffer (pH 6.8) containing bromophenol blue and glycerol. After dyeing with Coomassie Brilliant Blue, the gels were judged with an EC3 imaging system. The HCM solution was dialyzed against distilled water using a membrane (MWCO: 3500) for 2 days to remove the phosphate, and then lyophilized. After that, the lyophilized powder was dissolved in phosphate buffer solution (pH 7.4) at a concentration of $1.3 \mathrm{mg} \mathrm{mL}^{-1}$. The concentration of $\mathrm{Hb}$ was determined by the absorbance peak appearing at $405 \mathrm{~nm}$ in the UV spectrum. Finally, the mass ratio of $\mathrm{Hb}$ to PMAG- $b$-PMAA- $b$-PBMA micelles (Hb conjugation ratio) was quantified according to a $\mathrm{Hb}$ standard curve. The $\mathrm{Hb}$ conjugation ratio was calculated by means of eqn (1):

$$
\mathrm{Hb} \text { conjugation ratio }=\frac{C_{\mathrm{Hb}}}{C_{\text {polymer }+\mathrm{Hb}}-C_{\mathrm{Hb}}} \times 100 \%
$$

\subsection{Preparation of the DOX-labeled HCMs}

$20 \mathrm{mg}$ of PMAG- $b$-PMAA- $b$-PBMA and $4 \mathrm{mg}$ of DOX preprocessed by triethylamine were dissolved in $5 \mathrm{~mL}$ of DMF. Next, the solution was dialyzed (MWCO: 3500) against phosphate buffer solution ( $\mathrm{pH} 7.4$ ) for $24 \mathrm{~h}$ and centrifuged to remove free DOX. Then, the $\mathrm{Hb}$ was conjugated on the DOX-loaded PMAG- $b$ PMAA- $b$-PBMA as described in the above section. The whole process was protected from light. Finally, the DOX-loaded HCMs were obtained.

\subsection{Characterization}

Proton nuclear magnetic resonance $\left({ }^{1} \mathrm{H}\right.$ NMR) spectra, which indicate the chemical constitution and number-average molecular weights of PMAG, PMAG- $b$-PMAA and PMAG- $b$-PMAA- $b$-PBMA, were recorded on a Bruker DMX-400 nuclear magnetic resonance (NMR) instrument operating at $400 \mathrm{MHz}$. FTIR spectra of the polymers were obtained on a Bruker Vector-22 Fourier transform infrared spectrophotometer. The morphology of the micelles was measured by transmission electron microscopy (TEM) (JEOL JEM$1200 \mathrm{EX}, \mathrm{JPN}$ ) operating at an acceleration voltage of $80 \mathrm{kV}$. The hydrodynamic diameter and stability of the micelles were measured by dynamic light scattering (DLS) (Malvern nanozS-90 size analyzer, UK). The critical micelle concentration (CMC) was determined by the fluorescence probe technique, which was carried out on a RF-5301 spectrophotometer.

\section{$2.8 \mathrm{O}_{2}$ binding ability of the HCMs}

The HCM solution was deoxidized by sodium hyposulfite and oxidized in an oxygen atmosphere sequentially. Simultaneously, the process was recorded by a UV spectrometer.

\subsection{In vitro cytotoxicity study}

In vitro cytotoxicity was assessed by an MTT assay. Briefly, Hek 293 cells and Hela cells were seeded in 96-well plates at a density of $1 \times 10^{3}$ cells per well and incubated at $37^{\circ} \mathrm{C}$ for $16 \mathrm{~h}$ to be excellently adhesive. Then, DMEM serum-free medium was removed and HCMs at different concentrations (10, 25, 50, 100, 250 and $500 \mu \mathrm{g} \mathrm{mL}^{-1}$ ) were added to the corresponding six wells. After the cells had been incubated for $4 \mathrm{~h}$, the polymer solutions were disposed of. Then, $100 \mu \mathrm{L}$ of MTT solution (0.5 mg mL $\mathrm{mL}^{-1}$ in DMEM serum-free medium) was added. After incubation for $4 \mathrm{~h}, 100 \mu \mathrm{L}$ of DMSO was added into each well and shaken for $10 \mathrm{~min}$. The absorbance of formazan crystals was read at $570 \mathrm{~nm}$ using a microplate spectrophotometer. The cell viability was calculated by means of eqn (2):

$$
\text { Cell viability }=\frac{\mathrm{OD}_{570(\text { sample })}-\mathrm{OD}_{570(\text { blank })}}{\mathrm{OD}_{570(\text { control })}-\mathrm{OD}_{570(\text { blank })}} \times 100 \%
$$

\subsection{Cellular uptake}

To demonstrate that DOX-loaded HCMs can specifically recognize cancer cells and show an enhanced accumulation in cancer cells, we investigated the cellular uptake behavior of DOXloaded HCMs using Hela cells and Hek 293 cells. Hela cells and Hek 293 cells were seeded in a 12-well plate at a density of 1 $\times 10^{5}$ cells per well and incubated at $37^{\circ} \mathrm{C}$ for $24 \mathrm{~h}$ to be excellently adhesive. Then, the DMEM serum-free medium was removed and the cells were washed three times with $\mathrm{PBS}(\mathrm{pH}$ 7.4). The cells were incubated with DOX-loaded HCMs at a concentration of $6 \mu \mathrm{g}$ DOX per $\mathrm{mL}$ in 1640 serum-free medium for $4 \mathrm{~h}$. After the medium was removed, the cells were washed five times and then fixed with $4 \%$ formaldehyde for $10 \mathrm{~min}$. Prior to being photographed by CLSM, the cells were stained by DAPI for $10 \mathrm{~min}$ and washed with PBS three times. The excitation and emission wavelengths of DOX were $561 \mathrm{~nm}$ and $458 \mathrm{~nm}$ respectively.

In the cellular uptake studies by flow cytometry, the Hela cells and Hek 293 cells were seeded in a 6-well plate at a density of $2 \times 10^{5}$ cells per well and incubated at $37{ }^{\circ} \mathrm{C}$ for $24 \mathrm{~h}$ to achieve $80-90 \%$ confluence. Then, the DMEM serum-free medium was removed and the cells were washed three times with PBS (pH 7.4). The cells were incubated with DOX-loaded HCMs at a concentration of $6 \mu \mathrm{g}$ DOX per mL in 1640 serumfree medium for $4 \mathrm{~h}$. After the medium was removed, the cells were washed five times. The cells were then trypsinized, centrifuged, and washed twice with cold PBS. Finally, the samples were resuspended in $0.5 \mathrm{~mL}$ of PBS. The mean fluorescence intensity of the gated viable cells was quantified. Hela cells and Hek 293 cells without any treatment were used as a control.

\section{Results and discussion}

\subsection{Synthesis of the polymers}

The triblock copolymer PMAG- $b$-PMAA- $b$-PBMA was successfully synthesized via sequential triple RAFT polymerizations, as shown in Scheme 2, which has been hardly reported previously. 
${ }^{1} \mathrm{H}$ NMR spectra of the monomer and polymers are shown in Fig. 1. The ${ }^{1} \mathrm{H}$ NMR spectrum of MAG in $\mathrm{D}_{2} \mathrm{O}$ is shown in Fig. 1(A). The signals at $5.21 \mathrm{ppm}$ and $4.76 \mathrm{ppm}$ are due to the anomeric $\alpha-\mathrm{CH}$ and $\beta-\mathrm{CH}$ protons $(\mathrm{a}+\mathrm{b}$ ) of the glucose ring, and the signals at 3.96-3.42 ppm are attributed to the remaining six protons (c) of the glucose ring. The signals of the $\mathrm{Me}-\mathrm{C}=\mathrm{CHH}$ (d), $\mathrm{Me}-\mathrm{C}=\mathrm{CH} H$ (e) and $-\mathrm{CH}_{3}$ (f) protons adjacent to the carbon-carbon double bond appear at $5.69 \mathrm{ppm}, 5.46 \mathrm{ppm}$ and $1.92 \mathrm{ppm}$, respectively. The ratio between the integral areas of $d$, $\mathrm{e}$, $\mathrm{f}$ and $\mathrm{a}+\mathrm{b}$ is $1: 1: 3: 1$, which means a carbon-carbon double bond was successfully introduced to the glucose ring. Fig. 1(B) displays the ${ }^{1} \mathrm{H}$ NMR spectrum of PMAG in $\mathrm{D}_{2} \mathrm{O}$. Every proton of the homopolymer showed its corresponding characteristic signals in the spectrum. The MW of PMAG was calculated by the integral areas of protons on the CPDN (8.24-7.52 $\mathrm{ppm}$ ) and the anomeric carbon (5.25-4.75 ppm). The MW value of PMAG is $7600 \mathrm{~g} \mathrm{~mol}^{-1}$. Fig. 1(C) displays the ${ }^{1} \mathrm{H}$ NMR spectrum of PMAG- $b$-PMAA in DMSO. The signal around 13.0$12.0 \mathrm{ppm}$ is attributed to the protons on the carboxyl group of methacrylic acid. The molar ratio between MAG and MAA was calculated by the integral areas of the protons on the anomeric carbon and the carboxyl group. The MW value of PMAG- $b$-PMAA
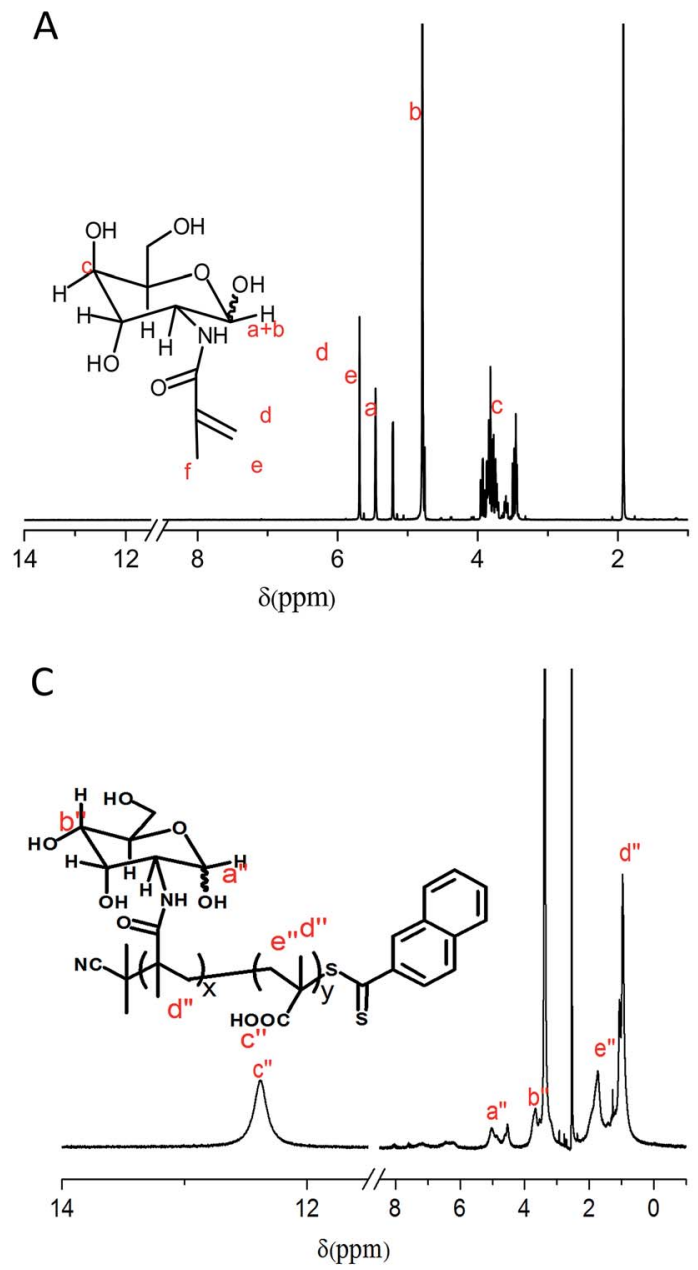

is $14000 \mathrm{~g} \mathrm{~mol}{ }^{-1}$. Fig. 1(D) displays the ${ }^{1} \mathrm{H}$ NMR spectrum of PMAG- $b$-PMAA- $b$-PBMA in DMSO. The signal of $\mathrm{O}=\mathrm{C}-\mathrm{O}-\mathrm{CH}_{2}-$ on butyl methacrylate presents around 3.76-3.50 ppm, which indicates that BMA units were introduced to the copolymer chain. The molar ratio between BMA and MAA was calculated by the integral areas of the protons on the methylene adjacent to the ester bond and the carboxyl group. The MW value of PMAG$b$-PMAA is $24000 \mathrm{~g} \mathrm{~mol}^{-1}$.

The FTIR spectra of the polymers (as shown in Fig. S1†) simultaneously imply that the triblock copolymer PMAG- $b$ PMAA- $b$-PBMA was prepared successfully.

\subsection{Characterization of the micelles}

The amphiphilic copolymer self-assembled into micelles in phosphate buffer solution using the dialysis method. The CMC of PMAG- $b$-PMAA- $b$-PBMA is $5 \times 10^{-4} \mathrm{~g} \mathrm{~L}^{-1}$ as determined by the fluorescence probe technique (as shown in Fig. $\mathrm{S} 2 \dagger$ ).

To further investigate the properties of the micelles, the size and morphology of the PMAG- $b$-PMAA- $b$-PBMA micelles and HCMs were characterized by DLS and TEM. Fig. 2(A) shows the size distribution detected by DLS of the PMAG- $b$-PMAA- $b$-PBMA
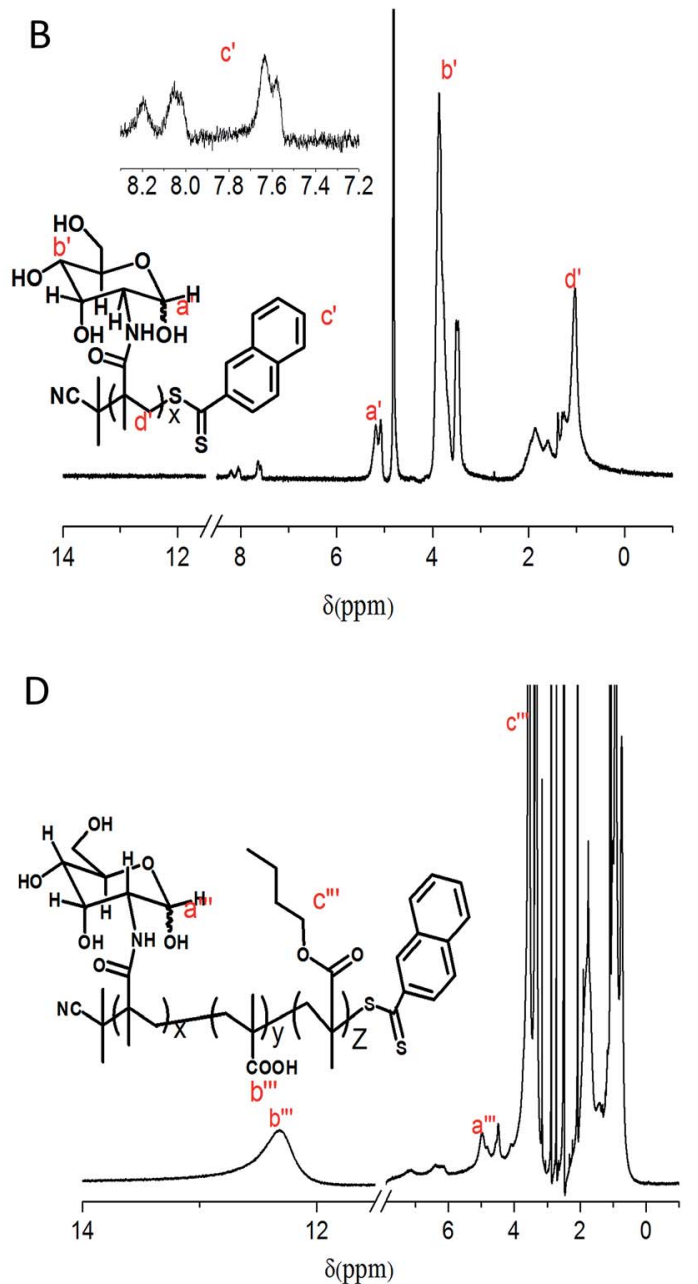

Fig. $1{ }^{1} \mathrm{H}$ NMR spectra of the monomer and polymers (A) MAG in $\mathrm{D}_{2} \mathrm{O}$, (B) PMAG in $\mathrm{D}_{2} \mathrm{O}$, (C) PMAG- $b$-PMAA in DMSO and (D) PMAG- $b$-PMAA- $b-$ PBMA in DMSO. 


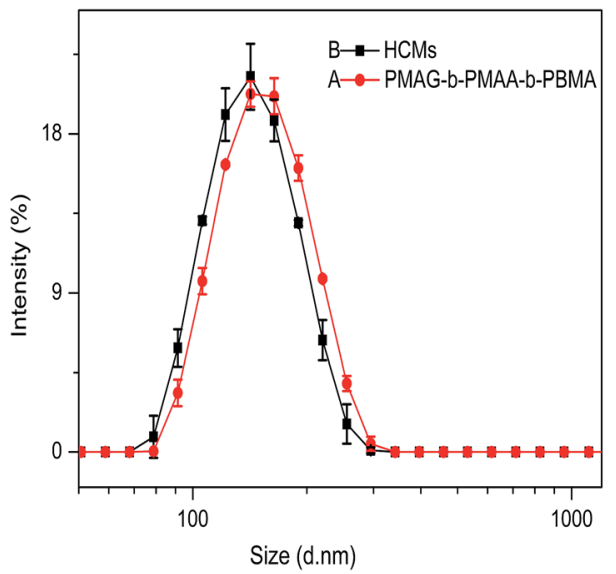

Fig. 2 The size distribution detected by DLS of (A) PMAG- $b$-PMAA- $b-$ PBMA and (B) HCMs.

micelles. It is found that the diameter of the PMAG- $b$-PMAA- $b$ PBMA micelles is around $158 \mathrm{~nm}$. Compared to the PMAG- $b$ PMAA- $b$-PBMA micelles, the HCMs exhibit a smaller diameter around $147 \mathrm{~nm}$ as shown in Fig. 2(B). The variation could be ascribed to the $\mathrm{Hb}$ conjugated to the PMAG- $b$-PMAA- $b$-PBMA chain, resulting in the consumption of carboxyl groups on MAA. Naturally, the repulsive force between hydrophilic chains decreases so that the micelles shrink slightly. Both of these two micelles have a very low PDI, about 0.05 , which means that the micelles prepared in this paper are equipped with good dispersity and uniformity in the aqueous phase. To further evaluate the stability of the micelles, both of these two micelles were characterized by DLS after being stored at $4{ }^{\circ} \mathrm{C}$ for 30 days. The diameter and PDI of the micelles remain unchanged (as shown in Fig. S3†).

Fig. 3 shows the morphology of the PMAG- $b$-PMAA- $b$-PBMA micelles and HCMs. As shown in Fig. 3, the PMAG- $b$-PMAA- $b$ PBMA micelles and HCMs are well dispersed in the form of spherical nanoparticles. In addition, the diameters of these two micelles determined by TEM are 81 and $73 \mathrm{~nm}$, respectively. This difference between the micelle size measured by TEM and DLS should be ascribed to the fact that the former is the morphological size of the micelles in the solid state, whereas the latter reveals the hydrodynamic diameter of the micelles in water. However, what is most important is that the diameter variation tendency from micelles to HCMs obtained by these two measurements keeps consistent.

\subsection{Synthesis of the HCMs}

$\mathrm{Hb}$ was conjugated to the triblock copolymer through a condensation reaction between the carboxyl groups on PMAA and the amino groups on $\mathrm{Hb}$. SDS-PAGE is a normal electrophoresis technique that is used to isolate proteins on lanes of polyacrylamide gel. Proteins can be decomposed into subunits with a small molecular weight after denaturing by SDS. Then, the subunits migrate under the effect of an electric field and the migration rate mainly depends on the molecular weight of the subunit. ${ }^{33}$ Therefore, SDS-PAGE was adopted to document the changes in the molecular weight of $\mathrm{Hb}$ after conjugating to PMAG- $b$-PMAA- $b$-PBMA (Fig. 4(A)). An obvious blue band presented around $15 \mathrm{kDa}$ on lane a (pure $\mathrm{Hb}$ ), which is due to $\mathrm{Hb}$ decomposing into four subunits with a small molecular weight. In the same way as lane $\mathrm{a}$, lane $\mathrm{b}$ ( $\mathrm{Hb}$ mixed physically with the polymers) showed a blue band around $15 \mathrm{kDa}$. This result indicates that the polymers mixed physically with $\mathrm{Hb}$ did not affect the molecular weight of the subunits that are associated with the migration rate. However, a broad band appeared above $44 \mathrm{kDa}$ on lane c (HCMs), which was entirely different from the above two lanes. This indicates that $\mathrm{Hb}$ conjugated to the polymers migrates slower than pure $\mathrm{Hb}$ or $\mathrm{Hb}$ mixed physically with the polymers. Furthermore, it is also demonstrated that $\mathrm{Hb}$ was successfully conjugated onto PMAG- $b$-PMAA- $b$-PBMA.

Furthermore, the conjugation of $\mathrm{Hb}$ was quantified. Generally, $\mathrm{Hb}$ exists as MetHb, which exhibits a typical absorbance
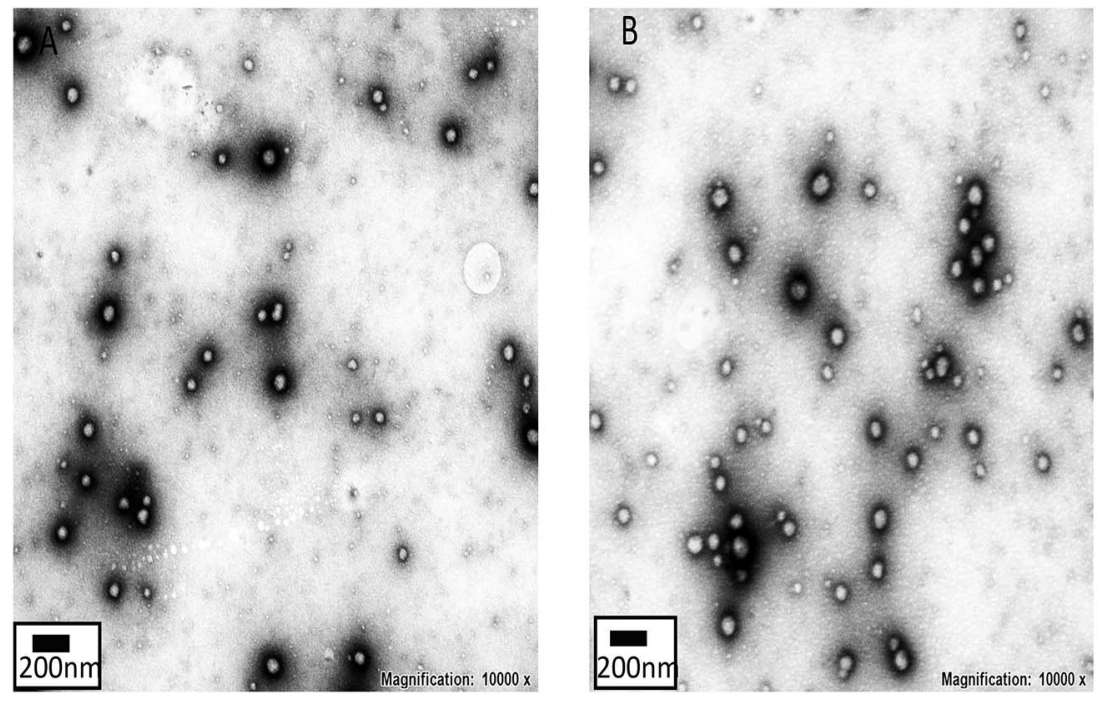

Fig. 3 TEM images of the (A) PMAG- $b$-PMAA- $b-P B M A$ micelles and (B) HCMs. 

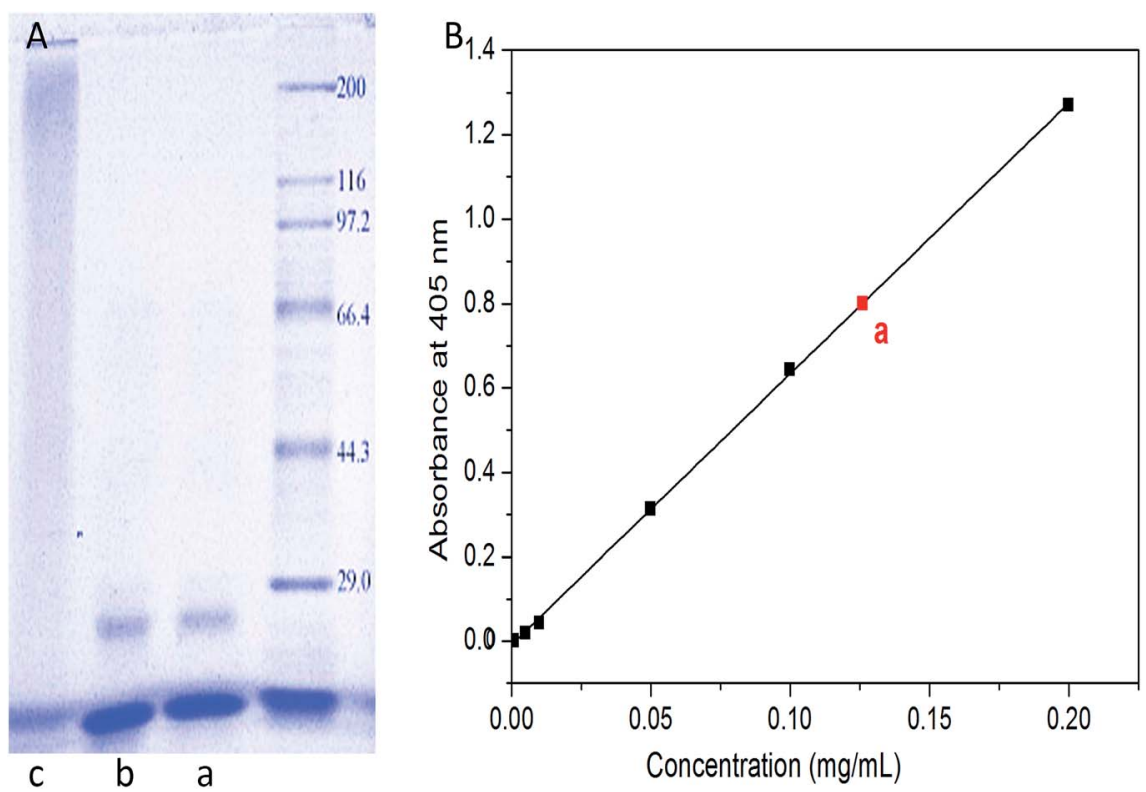

Fig. 4 Characterization of $\mathrm{Hb}$ conjugation onto the micelles: (A) SDS-PAGE of (a) pure $\mathrm{Hb}$, (b) Hb mixed physically with the polymers and (c) the HCMs; (B) the standard curve of hemoglobin in PBS (pH 7.4).

peak at $405 \mathrm{~nm}$. Therefore, the concentration could be determined by the absorbance at $405 \mathrm{~nm}$. The absorbance at $405 \mathrm{~nm}$ of $\mathrm{Hb}$ phosphate buffer solution at different concentrations $(0$, $0.001,0.005,0.01,0.05,0.1$ and $0.2 \mathrm{mg} \mathrm{mL}^{-1}$ ) was recorded by a UV-vis spectrophotometer. Then, the $\mathrm{Hb}$ standard curve was obtained through the absorbance as a function of $\mathrm{Hb}$ concentration. Point a in Fig. 4(B) is attributed to the sample that we prepared with a concentration of $0.126 \mathrm{mg} \mathrm{mL}^{-1}$. Consequently, the $\mathrm{Hb}$ conjugation ratio was calculated as $10.7 \%$. In addition, the conversion rate was calculated as $77 \%$, which indicates that the condensation reaction between $\mathrm{Hb}$ and the polymer is a relatively effective method of conjugation.

\section{4 $\mathrm{O}_{2}$ binding ability of the HCMs}

$\mathrm{Hb}$ has four subunits, each of which consists of a peptide chain and a heme. The ferrous ion on the heme can bind four oxygen molecules to make the oxygen-carrying ability come true. Generally, $\mathrm{Hb}$ exposed to air, which is in a ferric state, is referred to as MetHb without the capacity of carrying oxygen. Only when MetHb is transformed into OxyHb which is in the ferrous state can $\mathrm{Hb}$ bind oxygen. This transformation process can be recorded via the variation of the characteristic UV absorption peak ranging from 400 to $430 \mathrm{~nm}$; MetHb shows a Soret peak at $405 \mathrm{~nm}$, whereas the spectrum of OxyHb shows a Soret peak at $412 \mathrm{~nm}$. Therefore, in order to investigate the $\mathrm{O}_{2}$ binding ability of the HCMs, we used a UV spectrometer to record the transformation process (as shown in Fig. 5). Fig. 5(A) displays the UV spectrum of the HCM solution without any treatments. A Soret peak at $405 \mathrm{~nm}$ indicates the characteristic of MetHb. Fig. 5(B) shows the UV spectrum of the HCM solution after being deoxidized by sodium hyposulfate. A peak appears at $427 \mathrm{~nm}$, signifying that MetHb was transformed into deoxyHb after being deoxidized by sodium hyposulfate. Fig. 5(C) shows the UV spectrum of the HCM solution after it was oxidized by $\mathrm{O}_{2}$. A Soret peak appears at $412 \mathrm{~nm}$, implying that deoxyHb was transformed into OxyHb after binding to oxygen, which certifies that the HCMs have the capacity to carry oxygen. In addition, when excessive oxygen was fed, OxyHb was oxidized to MetHb, with the characteristic absorbance peak reverting to $405 \mathrm{~nm}$. This demonstrates that the synthetic procedure did not destroy the redox activity of hemoglobin, which is the key to binding oxygen. Simultaneously, considering a polymer solution without $\mathrm{Hb}$ as the blank control group, the appearance of these characteristic peaks and the transformation process could also indicate the successful conjugation of hemoglobin onto the micelles. In addition, the quantification of the oxygen binding

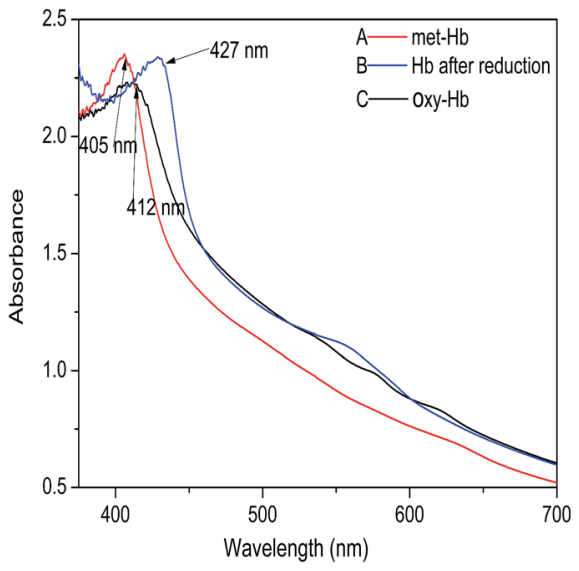

Fig. 5 UV absorption spectra changes of the HCMs (A) in the original state, (B) after being reduced by sodium hyposulfate and (C) binding oxygen. 


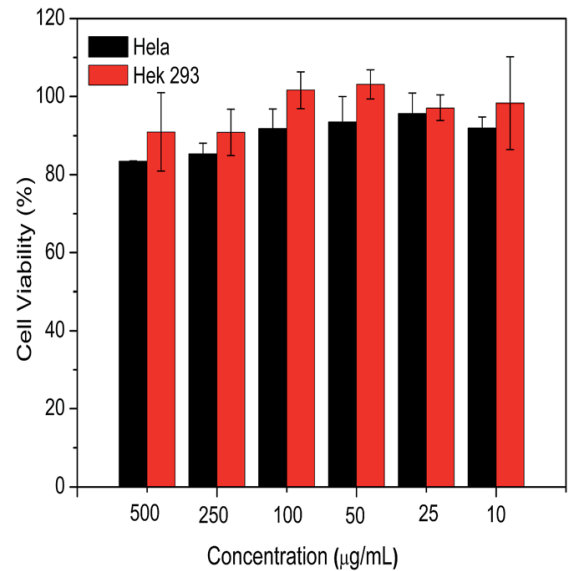

Fig. 6 The cell viability of Hela cells and Hek 293 cells after incubation with different concentrations of the HCMs for $4 \mathrm{~h}$.

efficiency is being undertaken, which will be published elsewhere.

\subsection{In vitro cytotoxicity study}

To evaluate the biocompatibility of the HCMs prepared in this paper, a preliminary estimation of the cytotoxicity against Hela cells and Hek 293 cells was performed by an MTT assay. As shown in Fig. 6, after incubation with the HCMs over a wide range of concentrations, the Hek 293 cells possessed over $90 \%$ viability, and particularly, almost no cytotoxicity was detected below a concentration of $100 \mu \mathrm{g} \mathrm{mL}^{-1}$. As for the Hela cells, below a concentration of $100 \mu \mathrm{g} \mathrm{mL}^{-1}$, the cell viability was over

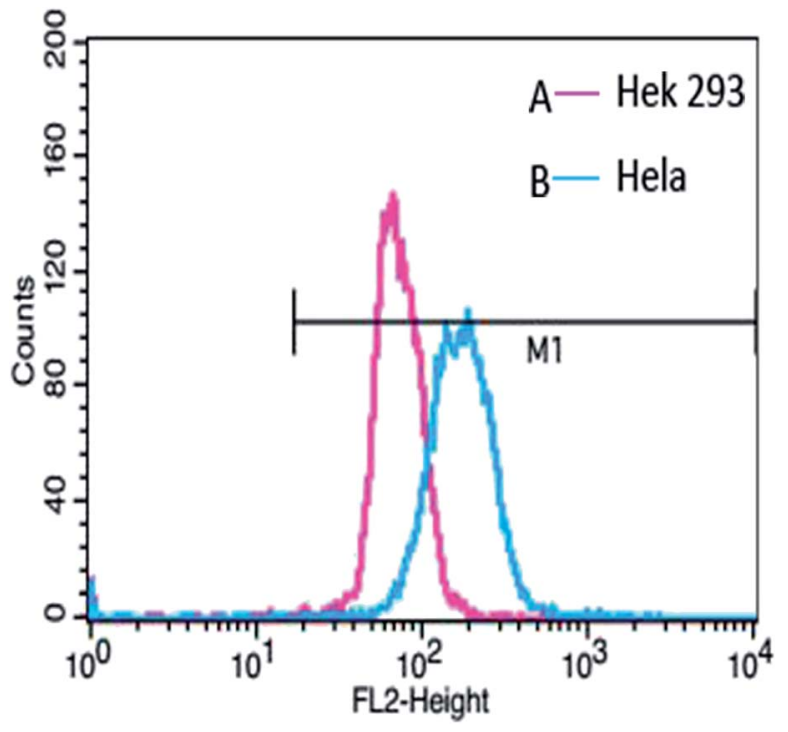

Fig. 8 Flow cytometry analysis of the DOX-loaded HCMs in (A) Hek 293 cells and (B) Hela cells.

$90 \%$. Only slight cytotoxicity was observed at 250 and $500 \mu \mathrm{g}$ $\mathrm{mL}^{-1}$, but the cell viability also remained around $85 \%$. The result of the cytotoxicity against normal and cancer cells indicates that the HCMs are non-cytotoxic, biocompatible and suitable as a drug nanocarrier.

\subsection{Cellular uptake}

In order to confirm that the HCMs are equipped with the ability to recognize cancer cells, we performed cellular uptake
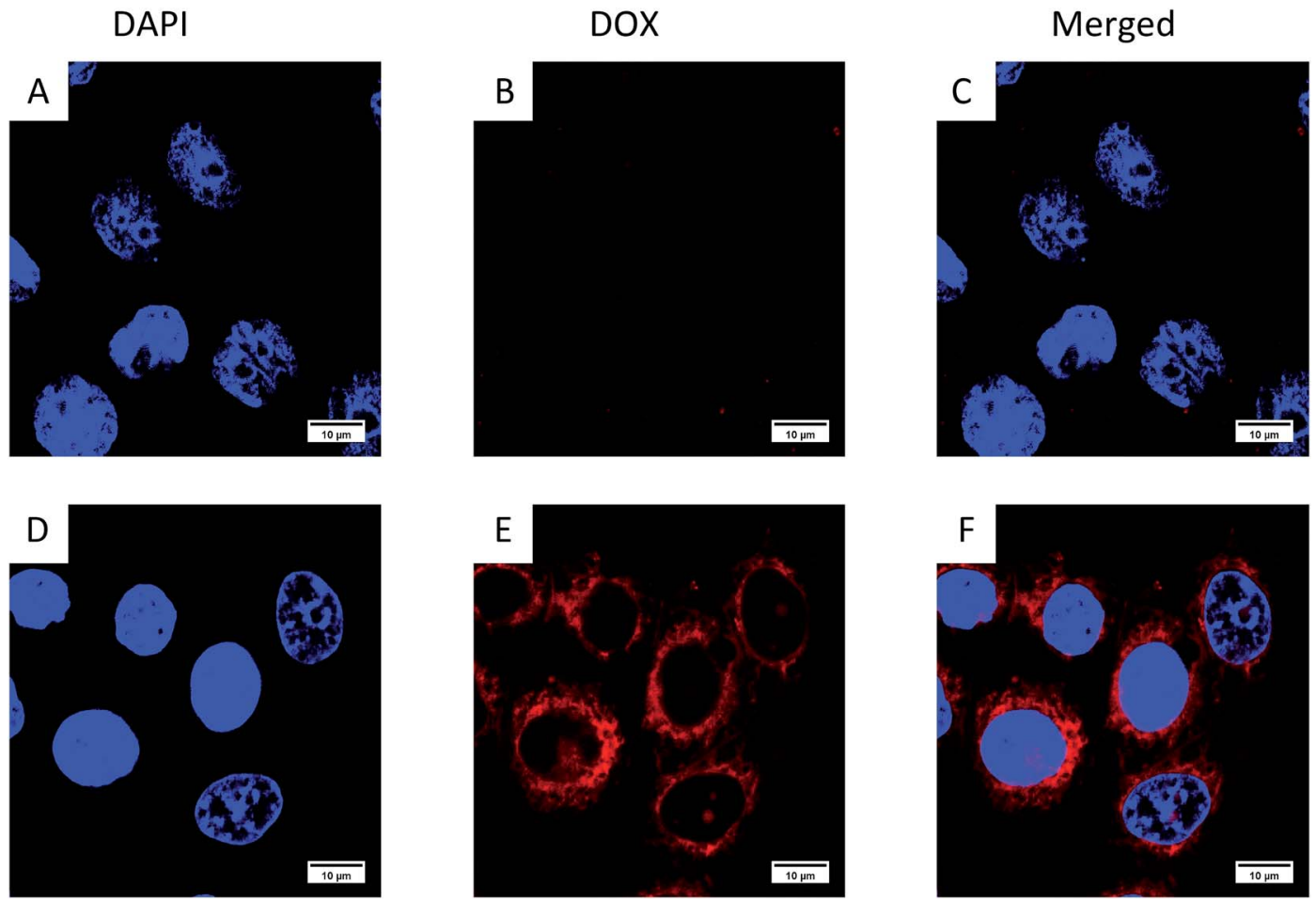

Fig. 7 Cellular uptake of the DOX-loaded HCMs in (A-C) normal cells (Hek 293 cells) and (D-F) tumour cells (Hela cells). 
characterization in Hela cells (a kind of tumour cell) and Hek 293 cells (a kind of normal cell), qualitatively analyzed by CLSM (Fig. 7) and quantitatively analyzed by flow cytometry (Fig. 8). More DOX-loaded HCMs accumulated in Hela cells in contrast to Hek 293 cells, and hardly any DOX-loaded HCMs accumulated in Hek 293 cells after incubation for $4 \mathrm{~h}$. This result indicates that the HCMs show specific recognition for Hela cells. This notable result could be attributed to the overexpressed GLUT1 on the Hela cells. Glucose, which was modified on the HCMs in abundance, can bind to GLUT1 very well, resulting in the accumulation of more HCMs in the Hela cells. Therefore, it was demonstrated that the HCMs can specifically recognize cancer cells. Considering the obvious differences of DOX-loaded HCM accumulation between cancer cells and normal cells, the HCMs may target tumours in vivo. Further characterization of the tumour targeting ability will be carried out.

\section{Conclusions}

In this study, we designed a nanocarrier functionalized with specific recognition of cancer cells and oxygen carrying ability. The multifunctional nanocarrier was obtained via conjugation of $\mathrm{Hb}$ onto polymers. The triblock copolymer PMAG- $b$-PMAA- $b$ PBMA was synthesized via RAFT polymerization. $\mathrm{Hb}$ was conjugated onto the polymers through a condensation reaction. The hemoglobin-based oxygen carrier could self-assemble into spherical micelles, which were equipped with narrow polydispersity, a mean diameter of $147 \mathrm{~nm}$, and excellent stability. More importantly, the HCMs were demonstrated to hold good capacity for binding oxygen. In vitro cytotoxicity detection revealed that normal cells and cancer cells showed high cell viability (over 90\%) below a micelle concentration of $250 \mu \mathrm{g}$ $\mathrm{mL}^{-1}$, which means that the HCMs are biocompatible. In addition, the oxygen nanocarrier was confirmed to show favorable recognition of cancer cells via the cellular uptake of DOX-loaded HCMs by Hela cells in comparison to normal cells. Consequently, the HBOC that we prepared is a promising nanocarrier for tumour therapy.

\section{Conflicts of interest}

There are no conflicts of interest to declare.

\section{Acknowledgements}

We acknowledge Prof. Guping Tang, Miss Yang Li, Miss Qi Chen, Mr Guojun Huang and Mr Yuxuan Chen at Zhejiang University for their assistance with the cell tests. This research is supported by the National Natural Science Foundation of China (21274124, 21374069).

\section{References}

1 P. Vaupel, K. Schlenger, C. Knoop and M. Hockel, Cancer Res., 1991, 51, 3316-3322.
2 J. M. Brown and W. R. Wilson, Nat. Rev. Cancer, 2004, 4, 437447.

3 K. Ghattass, R. Assah, M. El-Sabban and H. Gali-Muhtasib, Curr. Cancer Drug Targets, 2013, 13, 670-685.

4 R. Zhang, X. J. Song, C. Liang, X. Yi, G. S. Song, Y. Chao, Y. Yang, K. Yang, L. Z. Feng and Z. Liu, Biomaterials, 2017, 138, 13-21.

5 A. Casas, G. Di Venosa, T. Hasan and A. Batlle, Curr. Med. Chem., 2011, 18, 2486-2515.

6 D. A. Chan and A. J. Giaccia, Cancer Metastasis Rev., 2007, 26, 333-339.

7 P. Rouhi, S. L. Lee, Z. Cao, E. M. Hedlund, L. D. Jensen and Y. Cao, Cell Cycle, 2010, 9, 913-917.

8 K. M. Comerford, T. J. Wallace, J. Karhausen, N. A. Louis, M. C. Montalto and S. P. Colgan, Cancer Res., 2002, 62, 3387-3394.

9 J. L. Yuan and P. M. Glazer, Mutat. Res., Fundam. Mol. Mech. Mutagen., 1998, 400, 439-446.

10 Y. Lv, S. Zhao, J. Han, L. Zheng, Z. Yang and L. Zhao, OncoTargets Ther., 2015, 8, 1941-1948.

11 R. M. Phillips, Cancer Chemother. Pharmacol., 2016, 77, 441457.

12 M. Q. Wei, A. Mengesha, D. Good and J. Anne, Cancer Lett., 2008, 259, 16-27.

13 W. C. Huang, M. Y. Shen, H. H. Chen, S. C. Lin, W. H. Chiang, P. H. Wu, C. W. Chang, C. S. Chiang and H. C. Chiu, J. Controlled Release, 2015, 220, 738-750.

14 C. Chu, H. Lin, H. Liu, X. Wang, J. Wang, P. Zhang, H. Gao, C. Huang, Y. Zeng, Y. Tan, G. Liu and X. Chen, Adv. Mater., 2017, 29.

15 M. Yu, M. Dai, Q. Liu and R. Xiu, Cancer Treat. Rev., 2007, 33, 757-761.

16 H. Sakai, M. Yuasa, H. Onuma, S. Takeoka and E. Tsuchida, Bioconjugate Chem., 2000, 11, 56-64.

17 H. Sakai, K. Sou, H. Horinouchi, K. Kobayashi and E. Tsuchida, J. Intern. Med., 2008, 263, 4-15.

18 T. M. Chang, Trends Biotechnol., 2006, 24, 372-377.

19 R. Jahanban-Esfahlan, M. de la Guardia, D. Ahmadi and B. Yousefi, J. Cell. Physiol., 2017, 9999, 1-13.

20 M. Lu, C. Zhao, Q. Wang, G. You, Y. Wang, H. Deng, G. Chen, S. Xia, J. Zhao, B. Wang, X. Li, L. Shao, Y. Wu, L. Zhao and H. Zhou, Colloids Surf., B, 2016, 139, 171-179.

21 Y. Wang, L. Yan, B. Li, Y. Qi, Z. Xie, X. Jing, X. Chen and Y. Huang, Macromol. Biosci., 2015, 15, 1304-1313.

22 Q. Shi, Y. B. Huang, X. S. Chen, M. Wu, J. Sun and X. B. Jing, Biomaterials, 2009, 30, 5077-5085.

23 T.-h. Li, X.-b. Jing and Y.-b. Huang, Polym. Adv. Technol., 2011, 22, 1266-1271.

24 Y. X. Qi, T. H. Li, Y. P. Wang, X. Wei, B. Li, X. S. Chen, Z. G. Xie, X. B. Jing and Y. B. Huang, Macromol. Biosci., 2016, 16, 906-913.

25 B. Li, T. Li, G. Chen, X. Li, L. Yan, Z. Xie, X. Jing and Y. Huang, Macromol. Biosci., 2013, 13, 893-902.

26 M. Roveri, M. Bernasconi, J.-C. Leroux and P. Luciani, J. Mater. Chem. B, 2017, 5, 4348-4364.

27 L. Xu, Q. Bai, X. Zhang and H. Yang, J. Controlled Release, 2017, 252, 73-82. 
28 S. S. Hoseini and N. V. Cheung, Cancer Lett., 2017, 399, 4452.

29 S. Takeuchi, M. Baghdadi, T. Tsuchikawa, H. Wada, T. Nakamura, H. Abe, S. Nakanishi, Y. Usui, K. Higuchi, M. Takahashi, K. Inoko, S. Sato, H. Takano, T. Shichinohe, K. Seino and S. Hirano, Cancer Res., 2015, 75, 2629-2640.

30 R. E. Airley and A. Mobasheri, Chemotherapy, 2007, 53, 233256.
31 Y. Guo, Y. Zhang, J. Li, Y. Zhang, Y. Lu, X. Jiang, X. He, H. Ma, S. An and C. Jiang, ACS Appl. Mater. Interfaces, 2015, 7, 54445453.

32 F. Yuan, S. Wang, W. Lu, G. Chen, K. Tu, H. Jiang and L.-Q. Wang, J. Mater. Chem. B, 2015, 3, 4546-4554.

33 D. Li, H. Chen, S. Wang, Z. Wu and J. L. Brash, Acta Biomater., 2011, 7, 954-958. 